\title{
Ampliando una Página de Cortázar
}

(Notas sobre "Las babas del diablo")

La complejidad estructural de "Las babas del diablo", su apariencia de incoherente fragmentarismo, son poderosos estímulos para abandonar el cómodo escaño del lector y asomarse al territorio crítico.

El recuerdo de un artículo en que Cortázar teorizaba sobre el cuento como género literario, nos decide a afrontar la empresa. En ese ensayo se hermanaban en lo esencial el oficio del cuentista con el del fotógrafo:

No sé si ustedes han oído hablar de su arte a un fotógrafo profesional; a mí siempre me ha sorprendido el que se exprese tal como podría hacerlo un cuentista en muchos aspectos. ${ }^{1}$

Teniendo esto en cuenta, surge una primera intuición. Acaso exis$\tan$ relaciones entre aquellas afirmaciones teóricas y este cuento en particular. Quizá una trabajo sirva para explicar al otro y una mirada detenida y simultánea sobre ambos pueda revelarnos hasta qué punto teoría y práctica encuentran en este autor correspondencia.

Existe una anécdota superficial. Por razones de comodidad expositiva quiero llamarla, en adelante, A, y comprender en ella toda la acción desplegada por el protagonista el domingo 7 de noviembre (exactamente un mes antes de que comience el relato) desde que abandona su departamento hasta que, luego de recorrer las calles de París y captar con su cámara la escena ya descrita, vuelve al departamento, revela y amplía sus fotografías. Llamaré B a la acción transcurrida entre ese momento y aquél en que comienza a escribir el relato. Para el último

1 Julio Cortázar, "Algunos aspectos del cuento" Casa de las Américas, N" 15-16. Nov. 62-Febr. 63, pp. 3-14. 
lapso, que corresponde al tiempo que emplea en concluir la narración, le asignaré, finalmente, la denominación $C$.

Si quisiésemos creer que el asunto principal de este cuento es el episodio de la seducción a la que Michel y su cámara asisten como involuntarios testigos $\rightarrow$ que considero tema principal de $A-$ tendríamos que admitir necesatiamente que el conjunto de hechos que abarrotan las secciones $\mathrm{B}$ y $\mathrm{C}$, constituye un material de relleno de inusitada extensión Demasiadas serían las sendas abiertas hacia ninguna parte. Veamos en este punto qué opiniones sustenta Cortázar frente a la acumulación de material accesorio:

Un escritor argentino, muy amigo del boxeo, me decía que en ese combate que se entabla entre un texto apasionante y su lector, la novela gana siempre por puntos, mientras que el cuento debe ganar por knockout. Es cierto, en la medida en que la novela acumula progresivamente sus efectos en el lector, mientras que un buen cuento es incisivo, mordiente, sin cuartel desde las primeras frases. No se entienda esto demasiado literalmente, porque el buen cuentista es un boxeador muy astuto, $y$ muchos de sus golpes iniciales pueden parecer poco eficaces cuando, en realidad, están minando ya las resistencias más sólidas del adversario. Tomen ustedes cualquier gran cuento que prefieran, y analicen su primera página. Me sorprendería que encontraran elementos gratuitos, meramente decorativos.

Un cuento, como una fotografía lograda, presupone una ceñida limitación previa - ha afirmado Cortázar-, e intentando explicar tal analogía, agrega:

Fotógrafos de la calidad de un Cartier-Bresson o de un Brassai definen su arte como una parente paradoja: la de recortar un fragmento de la realidad, fijándole determinados límites, pero de manera tal que ese recorte actúe como una explosión que abre de par en par una realidad mucho más amplia, como una visión dinámica que trasciende espiritualmente el campo abarcado por la cámara. Mientras en el cine, como en la novela, la captación de esa realidad más amplia y multiforme se logra mediante el desarrollo de elementos parciales, acumulativos, que no excluyen, por supuesto, una síntesis que dé el "climax" de la obra, en una fotografía o un cuento de gran calidad se procede inversamente, es decir que el fotógraf̧o o el cuentịsta se ven precisados o a escoger y limitar 
una imagen o un acaecimiento que sean significativos, que no solamente valgan por sí mismos sino que sean capaces de actuar en el espectador o en el lector como una especie de apertura, de fermento que proyecta la inteligencia y la sensibilidad hacia algo que va mucho más allá de la anécdota visual o literatia contenidas en la foto o en el cuento. ${ }^{2}$

Sea entonces que Cortázar haya escrito su cuento para ilustrar una teoria o que haya ascendido a ésta desde su propia obra, ${ }^{3}$ todo parece afirmar la estrecha relación entre el ensayo que he venido citando y "Las babas del diablo", y setá aquél, por tanto, un auxiliar siempre presente en nuestro intento de penetrar hacia el significado inicial de éste.

Ya podemos aventurar que, de acuerdo a nuestra primera intuición, la anécdota $A$ es a la totalidad del cuento como una foto a la realidad que trata de captar: el acontecimiento ceñido y significativo que nos proyectará a algo que va mucho más allá de ella misma.

Y a ese fotógrafo que incursiona por terreno ajeno al tratar de relatarnos su historia valiéndose de palabras, le vamos viendo ya mayor relevancia que la que él mismo se otorga. Contra su pretensión de pasar desapercibido y su habitual inhabilidad para narrar, intensificada en particular para narrar esta historia, adivinamos el oculto designio de su creador que le reserva un rol más destacado en el cerrado universo de este cuento.

No hay contradicción censurable en la diferencia de habilidades que Michel evidencia. Ser un experto fotógrafo no lo habilita para ser un cuentista igualmente eficaz, como podríamos deducir apresuradamente de los fragmentos del ensayo transcritos. $Y$ es que la idea de significación, nos advierte Cortázar,

2 Con estas afirmaciones no pretende Cortázar ser original sino verdadero. Consciente o inconscientemente, la buena literatura ha reconocido siempre el valor "explosivo" de ciertos hechos mínimos. Azorín, en las antípodas de Cortázar en muchos aspectos, hizo toda su obra partiendo de una premisa análoga: la búsqueda del acto menudo pero suficientemente significativo, que es capaz de entregar una realidad más intensa que el suceso espectacular. $Y$ en el campo de la historiografía, no ha sido la aplicación puntual de tal método lo que ha permitido los hallazgos de Américo Castro?

3 Muy poco indica sobre la real cronologia de estos trabajos señalar las respectivas fechas de publicación. "Las babas del diablo" apateció (en Las armas secretas) en agosto de 1959, "Algunos aspectos del cuento", en febreto de 1963. 
no puede tener sentido si no la relacionamos con las de intensidad y de tensión, que ya no se refieren solamente al tema sino al tratamiento literario de ese tema, a la técnica empleada para desarrollar el tema.

El titubeo expresivo del narrador, sus continuas digresiones, sus vacilaciones ante la elección de la forma que debe escoger para contarnos su historia, contrastan notablemente con la expedita seguridad con que se desenvuelve en su oficio habitual. Cámara en mano recupera la confianza en sí mismo y sabe que no errará al elegir "la imperceptible fracción esencial", está "seguro de que atraparía poi fin el gesto revelador"."

Ia ampliación posterior de la fotografía no le entregará a su hacedor una realidad radicalmente diferente a la previamente intuída: lo que creyó ver era un intento de corrupción a un menor y lo que su arte le revela son sólo circunstancias agravantes de una misma realidad. Circunstancias que la hacen mucho más borrible, pero que no rectifican sustancialmente su percepción inicial.

Vayamos pues, relato adentro. Acaso un cambio de perspectiva al leerlo, nos ayude en nuestra empresa. A Michel es, justamente, una mirada en diagonal la que le deparó la revelación final.

nunca se me había ocurrido pensar que cuando miramos una foto de frente, los ojos repiten exactamente la posición y la visión del objetivo; son esas cosas que se dan por sentadas y que a nadie se le ocurre considerar... sin duda era la manera más perfecta de apreciar una foto, aunque la visión en diagonal pudiera tener sus encantos y aun sus descubrimientos.

Comience nuestra aproximación, según hace Aristóteles en su Poética y el sentido común aconseja, por lo que ocupa el primer lugar.

Ha declarado Cortázar que todos los cuentos que, en cuanto lector, le han resultado memorables, han tenido en común el ser incisivos desde la primera línea. No parece un desatino creer que al trocar su chaise-

4 No está de más advertir aquí la fundamental paradoja que va envuelta en el propósito de Cortázar: relatar impecablemente simulando que quien lo hace no domina los recursos narrativos. $Y$ todo ello, al servicio de la idea rectora del cuento. 
longue de lector hedonista por la severa mesa de escritor no echará al olvido las verdades que ha acuñado sino que se avendrá, más bien, a ponerlas en práctica.

Nunca se sabrá cómo hay que contar esto, si en primera persona o en segunda, usando la tercera del plural o inventando continuamente formas que no servirán de nada. Si se pudiera decir: yo vieron subir la luna, $o$ : nos me duele el fondo de los ojos, y sobre todo asi: tú la mujer rubia eran las nubes que siguen corriendo delante de mis tus sus nuestros vuestros sus rostros. Qué diablos.

Una lectura desprevenida de este primer párrafo no debería darle a los tres ejemplos de incorrección gramatical que él contiene, otro valor que el subordinado propio a todo ejemplo. Pero ya hemos dicho que nos propondríamos una forma intencionada de lectura y ella nos aconseja considerar esas tres oraciones como vinculadas al tema de la narración. En las tres frases "yo vieron subir la luna", "nos me duele el fondo de los ojos" y "tú la mujer rubia eran las nubes que siguen corriendo delante de mis tus sus nuestros vuestros sus rostros") su evidente incorrección sintáctica es de un mismo tipo: una pluralidad de sujetos pugnando por apoderarse de cada una de las acciones descritas.

$Y$ así, sin que medie ninguna declaración explícita, ya podríamos detectar, a lo menos, dos propósitos encubiertos: el de una cierta universalización de las situaciones que aquí se relatarán y el reconocimiento de que la realidad no es univoca sino variable, y se configura de acuerdo al sujeto que en cada caso la experimenta. ${ }^{5}$

Ahora bien, ¿por qué se anticipa a asegurar que las formas narrativas que pueda inventar para trasmitirnos la historia "no servirán de nada"? ¿A qué clase de inutilidad se está refiriendo? Es claro que nunca la visión suya será la misma del lector; ${ }^{\circ}$ ni la mía, analista; ni la tuya, lector mío. Pero ahí quedará; al menos, sobre el papel, como intento honesto del hablante. De Roberto Michel. Pero no es tal validez estética la que se está cuestionando ya en esa primera frase del cuento. Dentro del dominio artístico tales formas pueden o no tener utilidad, servir propósitos artísticos. Pero el arte no es toda la realidad. Acaso

5 Tampoco es novedoso el propósito de trasladar al arte esta afirmación. Bástenos recordar la película japonesa Rashomon que en forma insuperable ilustra esta tesis recogiendo la versión de un mismo hecho relatado por cuatro tes. tigos, a la vez verídicos y contradictorios.

"Lo que la estilística denomina "significado inicial" y "significado final", y cuya identificación total de antemano reconoce como imposble utópco. 
sea el instrumento capaz de captarla más hondamente, pero es - siempre de acuerdo al pensamiento del narrador- impotente para alterarla.

En virtud de esta declaración precoz podríamos comenzar ya a sospechar que la postura vital de Michel no es exclusivamente estética. ${ }^{7}$ Paralela a ella, o mejor, por encima de ella, hay una preocupación ética innegable. ${ }^{8}$

En el primer párrafo del cuento, que nos sitúa temporalmente en el sector que he llamado $C$ (y cuyo tema consiste en las dificultades que encuentra un narrador aficionado para contar objetivamente una historia que lo ha conmovido) advertimos ya puntos de contacto con las acciones A y B. Estos contactos no son ostensibles, descansan en el fondo de las tres oraciones ejemplificadoras ya citadas.

La preocupación "literatia" se manifiesta en el hecho de tener que escoger, desde el comienzo, una forma narrativa y no es una banalidad porque cualquiera que sea la forma escogida supone necesariamente haber descartado otras ópticas, cuando el carácter multifacético de la realidad pareciera exigir un ataque también múltiple. ${ }^{9}$

Es de notar el modo progresivo de las tres frases para aproximarse a los temas, nartativos que luego se desarrollarán en el cuento. La pri- mera oración es meramente ejemplar, neutra en relación con los tres argumentos principales. El yo apenas roza débilmente la zana $\mathrm{C}$. La segunda oración vincula hechos de las zonas B y C (el prolongado llanto de Michel antes de iniciar la narración le provoca este dolor que experimenta abora). La tercera, abraza elementos de las tres zonas.

Esta detención nos ha gratificado con una certeza que ya no nos abandonará en el resto del relato. Aunque las tres historias son temáticamente diferentes, ${ }^{10}$ están operando entre ellas activos vasos comunicantes. $\mathrm{Y}$ lo que puede parecer torpeza narrativa en Michel es, en

7 Concide, en este aspecto, con la propia actitud poética de Cortázar, la cual, como lo han reconocido sus críticos, está más comprometida con el quehacer interior que con la pretensión de un logro estético.

8 Actitud que se confirma cuando, recordando su aventura, afirma: "Lo importante, lo verdaderamente importante era haber ayudado al chico a escapar a tiempo..." No logra desprestigiar del todo su actitud, la declaración que sobre sí mismo emite el narrador desde la distancia que le ofrece el uso de la tercera persona: "Michel es puritano a ratos". La preocupación moral del putitano no queda invalidada por la circunstancia de que se la ejerza en forma rigurosa.

- No es éste problema exclusivo del género narrativo. Aun el hablante lírico se ve a veces enfrentado a la misma dificultad. Asi, Neruda, por ejemplo, se pregunta al emprender su Viaje por las costas del mundo (que no pierde el carácter lírico por estar escrito en prosa) si ha de empezar "por lo grande o lo pequeño, lo de adentro o lo de afuera, si por la chaqueta o por el corazón".

10 No llame a engaño el hecho de que se sucedan temporalmente, de que compartan más o menos un mismo lugar en el espacio, ni de que en todas ellas csté presente Roberto Michel. 
efecto, astucia narrativa de Cortázar. Los manoteos que aquél parece lanzar al aire, son golpes que éste nos está propinando a la línea baja. Golpes que aun no acusamos pero que ya producirán su efecto.

Esta técnica "solapada", tan grata a Cortázar, queda de manifiesto, por ejemplo, en la forma como van siendo incorporados los personajes al relato. La mujer rubia ya ha aparecido en el primer párrafo, por cierto que desconectada de la acción inmediata (en eso precisamente consiste la "técnica del disimulo"). Su entidad no tiene aún más relieve que la luna, los ojos, las nubes; elementos que comparten el mismo domicilio segundón. En cuanto al chico, éste hará su irrupción como miembro integrante de una pareja, que cae dentro del inventario visual que Michel practica al llegar a la placita de la isla Saint-Louis.

No habia más que una pareja $y$, claro, palomas;...

El otro personaje del triángulo tampoco hace ruido al asomarse al relato:

Me hubiera gustado saber qué pensaba el hombre del sombrero gris sentado al volante del auto detenido en el muelle que lleva a la pasarela, y que leía el diario o dormía.

Como la pareja, también él forma parte casi indiferenciada del paisaje. O sea, todo lo contrario del procedimiento tradicionalmente consagrado por la narrativa prejoyciana, tan aficionada al redoble de tambores cada vez que echaba a la escena a alguna criatura.

En cuanto a Michel, el disimulo cortazariano es aun más perverso pues nunca se nos dice derechamente que él sea otra cosa que el simple testigo de una acción. Su crecimiento como personaje es progresivo pero como simultáneamente el lector está recibiendo otras informaciones a las que erradamente juzga más importantes para resolver el puzzle, el lector tierno e inocente abritá tamaños ojos para contemplar el gato mientras la liebre se pasea invisible, de puro evidente, ante sus ojos. ${ }^{11}$

En la inconsciente cacería que todo lector emprende. junto con la lectura de un cuento por atrapar pronto su meollo, el "de qué se trata",

11 Fue Edgar A. Poe en "La carta robada" quien introdujo este artificio de que lo mejor para ocultar algo sea exhibirlo. Chesterton lo aprovechó luego en "El hombre invisible". En ambos autores, esa sencilla anomalía de la observación es parte fundamental de la trama y permite finalmente la solución de los respectivos enigmas. En Cortázar vemos, por vez primera, el aptovechamiento natural de ese principio, aplicado a la técnica narrativa. 
me parece que nadie se contentará con esa presa fácil que es el bueno de Michel contorsionándose delante de nosotros. Ni a él ni a sus manotazos imprecisos le concedemos mayor trascendencia. Es un expositor inhábil demorándose en detalles accesorios. Un testigo que debe contar algo y luego desaparecer.

$Y$ eso es, precisamente, lo que él querría hacer. Apenas iniciado el segundo párrafo del cuento ya quiere irse por ahí a beber y que la máquina de escribir siga sola. "Sería la perfección" - afirma. ¿Por qué sería la perfección? La explicación que él of rece no la toma en serio. Ha dicho que, como hablará de una máquina (fotográfica), lọ mejor será que la historia la cuente otra máquina (de escribir). Pero no se engaña con tales paparruchas; sabe que si se va, la Remington quedará petrificada. Entonces, ¿debemos saltar simplemente por sobre esa afirmación, desestimándola del todo? No. Algo existe en la historia o en el que se dispone a narrarla $\rightarrow$ quizá en la relación entre ambosque haría preferible que él se retirase. ¿Es que no le interesa la tarea? No es eso. $\mathrm{Ha}$ dicho que alguien tiene que contarlo. La hipótesis válida es entonces la inversa: el tema, la tarea, le interesa demasicado...

Las extravagancias dilatorias parecen culminar cuando, a continuación, expresa:

Uno de todos nosotros tiene que escribir, si es que esto va a ser contado. Mejor que sea yo que estoy muerto, que estoy menos comprometido que el resto; yo que no veo más que las nubes y puedo pensar sin distraerme (ahí pasa otra, con un borde gris) y acordarme sin distraerme, yo que estoy muerto ( $y$ vivo, no se trata de engañar a nadie, ya se verá cuando llegue el momento, porque de alguna manera tengo que arrancar y he empezado por esta punta, la de atrás, la del comienzo, que al fin y al cabo es la mejor de las puntas cuando se quiere contar algo).

¿Cómo es esto? ¿El hablante está muerto? No. Está vivo. Entonces, ¿es falso que esté muerto? Tampoco. Estos estados de "muerte-vida" sólo son contradictorios en un limitado alcance biológico. Pero la realidad hombre, compuesta por millares de celdillas, se deja comparar en este sentido con un rascacielos visto en la noche desde el exterior. No diríamos de éste que está vivo en aquella zona que mantiene luces encendidas y simultáneamente muerto en el sector apagado? 
Estamos aun en el umbral del relato. Para entender esta anestesia que paraliza parte de la vitalidad de Michel nos vemos necesitados de algunas claves. Reconoce el autor que el párrafo transcrito no puede ser entendido todavía ("ya se verá cuando llegue el momento").

El momento llega, me parece, a continuación. Como será éste el último párrafo en el que me detendré, me tomo la libertad de transcribirlo completo:

De repente me pregunto por qué tengo que contar esto, pero si uno empezara a preguntarse por qué hace todo lo que hace, si unc se preguntara solamente por qué acepta una invitación a cenar (ahora pasa una paloma, y me parece que un gorrión) o por qué cuando alguien nos ha contado un buen cuento, en seguida empieza como una cosquilla en el estómago y no se está tranquilo hasta entrar en la oficina de al lado y contar a su vez el cuento; recién entonces uno está bien, está contento y. puede volverse a su trabajo. Que yo sepa nadie ha explicado esto, de manera que lo mejor es dejarse de pudores y contar, porque al fin y al cabo nadie se avergüenza de respirar o de ponerse los zapatos; son cosas que se hacen, y cuando pasa algo raro, cuando dentro del zapato encontramos una araña o al respirar se siente como un vidrio roto, entonces hay que contar lo que pasa, contarlo a los muchachos de la oficina o al médico. Ay, doctor, cada vez que respiro. . . Siempre contarlo, siempre quitarse esa cosquilla molesta del estómago.

Aplicando el modo de lectura oblicua que hemos hecho nuestro, afirmariamos que la historia que se avecina ha producido en el espectador narrador una sensación extraña, similar a la que él describe casualmente, una "cosquilla molesta en el estómago". O, más gráficamente, lo que experimenta quien al ir a calzar un zapato descubre una araña dentro de él, o al respirar siente como un vidrio roto. ¿No resultan del todo comprensibles cualquiera vacilación, precipitación, atolondramiento o repeticiones en un hablante cuyo ánimo ha sido previamente afectado de ese modo?

No querría proseguir el análisis más allá de esta primera página. Fue, por lo demás, el consejo que recibimos del propio Cortázar ("tomen ustedes cualquier gran cuento que prefieran y analicen su primera página").

Si hemos acertado, las claves halladas luego de la lectura del cuento $\mathrm{y}$ del análisis de su primera página, nos permiten adelantar una so- 
lución: el narzador, Roberto Michel, ha sido testigo' ${ }^{12}$ de un acto inmoral13 que provoca una fuerte respuesta de todo su ser. En sentido figurado, el "golpe" de dicha acción presenciada "mata" una parte importante de su personalidad. En busca de la catarsis depuradora se lanza a confesarnos su experiencia.

Quizá si nos empenásemos en computar su lenguaje desordenado, archivando y procesando los datos que tan generosa como caóticamente entrega al lector, ${ }^{14}$ podríamos trazar un retrato psicológico suyo tan acabado como el que realiza él mismo (partiendo de su intuición óptica, de su capacidad para ver) de la dispareja pareja dominical.

Pero quedémonos con lo esencial: se trata de una persona que agrega a su sentido moral una sensibilidad extrema, capaz de matices infinitesimales. Le atrae lo natural, la pura esponteneidad en la naturaleza y la inocencia en los seres humanos. ${ }^{15}$ De estas dos vertientes de donde extrae su fuerza, una, al comenzar el relato, se ha secado, y, en consecuencia, quien de ella se alimentaba, se ha marchitado, ha "muerto".

Digámoslo de una vez: hasta el momento de su aventura del 7 de noviembre, ${ }^{18}$ Michel era un hombre que mantenía una actitud entusiasta y confiada hacia el género humano. Luego de consumada la acción A pierde esa confianza fundamental. Su escepticismo lo aleja del compromiso con el género humano, lo decepciona vitalmente y lo obliga a replegarse en forma aun más intensa, casi exclusivamente y obsesivamente, en su actitud contempladora de la naturaleza.

Cabe naturalmente en este punto preguntarse por qué un hecho aislado que el narrador ha presenciado por azar, alcanza a comprometer

12 No me refiero sólo a su presencia física en la plaza como testigo parcial de un acto equívoco, sino a su calidad de testigo absoluto (luego de haber contemplado sus fotografías y haber "rumiado" lo sucedido) de un acto subjetivamente inequívoco.

13 Calificamos, siempre, desde la óptica del hablante.

14 $\mathrm{Si}$ toda esta información no fuese esencial, como propongo, considérese jcuán superflue sería! Y cuán discrepante la técnica narrativa de Cortázar con las teorias expuestas en el ensayo que hemos venido comentando.

15 Los ejemplos que aduce de la verdad que está ofrecéndose, y a la que hay el deber de estar atento, ilustran - también oblicuamente- sobre este aspcto: "ese brusco y delicioso rebote de un rayo de sol en una vieja piedra, o la carrera trenzas al aire de una chiquilla que vuelve con un pan o una botella de leche."

16 Completada, como ya he dicho, con el trabajo de laboratorio y de rumia. 
a todo el género humano en vez de circunscribirse a los sujetos implicados. Por lo general, sólo es capaz de producir este efecto desmoralizador desproporcionado lo que se ejecuta en contra nuestra. Cuando nos consideramos víctima de una perversidad o injusticia resulta una reacción casi natural que juzguemos a la humanidad entera (y no sólo a nuestros ofensores) una despreciable jaula de chacales. Sólo a personas de un temple especialísimo - $y$ creemos que Roberto Michel es de aquéllas - la afrenta a un tercero puede llegar a afectarle como pro pia. Pero, ¿no estará operando además, simultánea, secreta y quizá inconscientemente, una correspondencia entre el muchacho observado y su observante? ${ }^{17}$

¿No es acaso su propia "inocencia" también amenazada por las fuerzas que acosan al muchacho? ¿No es lo característico de éste una "disponibilidad parecida al viento y a las calles"? Y esa palabra -disponibilidad- que da remate a la descripción del muchacho, ¿no calza como anillo al dedo si buscásemos un calificativo para los afanes vitales de Roberto Michel?

Esta sutil identificación entre el chico en peligro y el narrador opera como un paralelismo permanente en la obra.

Ante las fuerzas del mal, llamémoslas así, corren ambos distinta suerte: gracias a la intervención de Michel el muchacho se salva; su salvador, en cambio, sucumbe. Pero el paraíso del chico es precario y seguirá siéndolo. ${ }^{18}$ Tarde o temprano, su disponibilidad será cogida. $\mathrm{Y}$ la inocencia perdida, ay, es un estado irrecuperable... Bien lo sabe Michel, que ya no escapará de aquello que la cámara le ha revelado. Auxiliado por el arte se ha asomado a la realidad última, a la naturaleza fangosa del ser humano y ya nada podrá devolverle su confianza. ${ }^{19}$

Una experiencia funesta ha escindido al narrador. Ya hemos nota-

17 Al concluir la biografía especulativa del chico, dice Michel: "esta biografia era la del chico $y$ la de cualquier chico..."

18 No es necesatio buscar aqui culpables del "asesinato" de Michel. Su desilusión, aunque la han provocado dos seres humanos, no se limita a ellos ni ellos representan un sector determinado de la variada gama humana. Quizá algunos pudieran deducir que el mal radica en la sociedad capitalista (se sobreentiende una promesa de dinero en la misión encomendada a la mujer rubia) o en la desviación erótica del hombre enharinado. No. No es posible señalar culpables $y$, condenándolos, extirpar, o al menos limitar el mal. Ni se trata de seres extraordinariamente perversos $\mathrm{ni}$ es su condición social o sus singularidades sicológicas las que determinan su acción. Hay algo que está, acaso, en la naturaleza humana, que la lleva indefectiblemente a caer, $\mathrm{g}$ a hacer caer, en redes a veces muy bellamente tendidas. Por eso, todo paraíso humano no puede menos que ser precario.

10 Esto, dentro de los límites del cuento. No tenemos por qué, como simples lectores, contagiarnos de escepticismo y pensar que Michel, de prolongar su existencia imaginaria, no tendria una segunda oportunidad sobre la tierra para constatar que la arcilla humana es bivalente, y digna depositaria, tantas veces, de confianza cabal. 
do su aparente incoherencia, sus frecuentes digresiones, su modo indirecto de hablar fluctuante (entre un mostrar lo que se oculta y un ocultar lo que se muestra).

Justo es observar, no obstante, que la anécdota (A) que desencadena los hechos está planteada con cietta nitidez, lujosa incluso de detalles, ${ }^{20}$ ofreciendo un contraste notable con la desordenada exposición del tema $B$ (que es, para nosotros, el asunto principal). $Y$ es que aquella situación se relata, y ésta, en cambio, debemos desentrañarla escuchando a nuestro interlocutor. Espiando el ser a través del habla, como aconseja Heidegger.

He venido sustentando la tesis de que este cuento se propone desarrollar una situación conflictiva: el choque entre la realidad mundana y la sensibilidad inocente de un artista. Tras ese propósito no es necesario suponer otro de mayor entidad. No vemos una moraleja implicita, ni siquiera una intención moralizante. Simplemente el retrato de una situación. No quiero decir con esto que no circulen ideas por el cuento. Como los hechos, éstas se encuentran entramadas y lo que intentaré a continuación es separar algunas del contexto sin detenerme en un análisis pormenorizado ni en su discusión. No pretende ser éste un trabajo exhaustivo ni quisiera alejarme de los límites reducidos que me he impuesto.

Ya he dicho que este cuento ilustra las ideas que Cortázar ha esgrimido acerca del cuento como género literario autónomo. Viene a desa. rollar literariamente la metáfora que utiliza para expresar la idea de la "ceñida limitación previa", según la cual un cuento es semejnte a una fotografia.

Es también ilustrativo de ciertas complejidades narrativas. El problema que cada escritor experimenta cuando intenta narrar algo, los obstáculos que dificultan su tarea. Por eso en "Las babas del diablo", junto con sumergirnos en el mundo que la narración despliega, estamos forzados a conservar cierta distancia necesaria para observar cómo ese mundo se va forjando. Esta empresa no es novedosa en sí. Recordemos, por citar sólo un ejemplo, el soneto "De repente" de Lope de Vega. El

20 Claro que tales detalles se nos entregan siempre desde la peculiar perspectiva del hablante. A pesar de sus esfuetzos por objetivarla, por hacerla equivalente al objetivo de su cámara, siempre habrá una subjetividad interpretando los estímulos que su ojo tecibe $y$ tiñendo inevitablemente las informaciones que nos ofrece. 
poeta va enunciando los problemas y resolviéndolos y así va quedando el soneto construído. Lo que valoriza el intento de Cortázar es que él no se limita a ese asunto, ya de por sí digno de todo un cuento, sino que es uno entre los varios temas imbricados. Su teoría literaria queda planteada e ilustrada dentro del contexto de una historia "verdadera". Como el personaje, por las razones catárticas ya anotadas, necesita relatarnos aquella historia, nosotros, lectores de doble intención, aprovechamos de fijarnos en las dificultades de su empresa. Dificultades que abaten a Michel pero de las que Cortázar emerge victorioso.

Como en casi toda gran obra de la literatura, está implícito en este cuento el problema de la realidad. Su carácter equivoco, multifacético y escurridizo. Esa complejidad de la realidad que no admite ser cercenada por un afán simplificador. Constituye uno de los méritos del cuento esa impresión de que en él se asiste a un trozo de vida sin elaborar, sin limitar, complejo, vario, irreducible. $Y$ frente a ella, la obra de arte (en este caso una fotografia) con su bifronte antagonismo de capacidad e impotencia: capacidad para descubrir la realidad, ${ }^{21}$ impotencia para modificarla. ${ }^{22}$

El antiquísimo asunto de la lucha entre las fuerzas del bien y del mal tiene también un lugar destacado en el complejo temático. Reconocer la pugna implica haber reconocido previamente la existencia de ambos combatientes. Inocencia es, por definición, el estado cándido, sin malicia, anterior a la maldad. Estado que no siempre se abandona por efecto de una acción propia. A veces, como en este relato, es el actuar ajeno el que descorre el velo que ocultaba la otra faz. Desde ese momento el universo toma el aspecto de una zona en disputa, dividida. Tal división aparece aquí desde lo más superficial (la doble nacionalidad y el doble oficio del narrador) a la evidencia latente de que en el muchacho confluyen dos caminos y dos son los destinos a los que puede ser conducido: al despertar en el infierno o al cielo de nubes purísimas. Andamiaje de baba y perfume. Babas del diablo, hilos de la Virgen... También es depositario de acciones encontradas: su ángel salvador obturando la cámara, sus demonios tratando de consumar su caída. ¿No

21 Por cierto que no es Cortázar el primero en advertir esta idea. Pero es válido como intento por dar expresión artística a las conjeturas que sobre el valor de la obra de arte otros han formulado, y entre ellos, Heidegger con perspicacia máxima. (vid. Martín Heidegger, El origen de la obra de arte).

22 Esta idea parece ser la que alcanza mayor relevancia en la versión cinematográfica de Antonioni, Blow-up. La foto, tal como en el cuento, permite al fotó grafo descubrir que se ha cometido un crimen, pero nada puede hacer no sólo por impedirlo sino por sancionarlo o, siquiera, denunciarlo. A la vez, la película se propone mostrar un fragmento significativo de un modo de vida contemporáneo. 
recuerda esta escena al Fatusto de Marlowe y la lucha que por obtener su alma entablan tras suyo un ángel de la luz y Mefistófeles?

La cantidad de ideas suspendidas en la atmósfera de este crento da una idea respecto a la ambición de los propósitos de Cortázar. Aunque en el instante de ser juzgado, lo sea un autor por sus frutos, no puede desestimarse la magnitud de la empresa abordada. $Y$ aunque fracase, el escalador que se lanza contra el Himalaya es vindicado por su pura ambición. "Ser poeta es ansiar", ha dicho Cortázar, "pero sobre todo obtener en la exacta medida en que se ansia". ${ }^{23}$ Aunque en este caso no hay derrota alguna que justificar, señalar este aspecto, nos parece, contribuye a enfatizar mejor su logro.

Ni es exclusivamente intelectual el universo que nos transmite Cortázar ni son sólo ideas, en consecuencia, los instrumentos que utiliza. Hay en "Las babas del diablo", como en el resto de su obra, toda una utilería simbólica presente. Sólo quiero referirme a tres de estos objetos, muy vinculados entre sí y significativos en el contexto total del relato: la ventana, la cámara fotográfica y las nubes.

La ventana es el objeto correspondiente a la fotografía ampliada que Michel ha clavado en la pared de su departamento. Son agujeros hacia la vida exterior. A través de la foto continúa sucediéndose la escena captada; en frente suyo, la ventana se abre a un desfile de nubes, o al cielo "perfectamente limpio". Dos rectángulos, dos mundos...

El magnético encanto de las ventanas ya ha sido anotado por Pedro Salinas:

...tiene ese misterioso rectángulo otra cualidad más, que nos explica su atractivo. Es la de encuadrar rigurosamente un fragmento de universo, de su tierra, su mar y su cielo ceñido entre una ordenación de cuatro líneas y por ende hacerlo más asequible a nuestra momentánea posesión, casi diría hasta nuestro dominio. Frente a un paisaje visto desde el exterior, la mirada casi no tiene lindes, yerra confusa por la vastedad, y el hombre se siente abrumado, en su humana limitación, por la grandiosa ilimitación de lo que lo rodea. En la oposición entre hombre y naturaleza, es ella la que triunfa a hotizonte desplegado. Pero si el mismo objeto humano

Ea Julio Cortázar, La vuelta al dia en orbenta mundos. Siglo XXI, México, 1967, p. 212. 
pone los ojos en idéntico paisaje, desde un cuarto, y tal como lo cuadra el marco de una ventana, el panorama se encuentra, por el arte maravilloso, limitado también. Limitado por una sencilla obra del hombre, por ese cuadrángulo de madera. ${ }^{24}$

Frente a la múltiple riqueza del mundo la ventana realiza la misma labor selectiva que la cámara fotográfica. El empeño poético de ambas es ver.

Después de completada la acción $A$ hay un desplazamiento progresivo del interés del protagonista desde su cámara a la ventana. La obvia explicación es que aquélla ha sido "culpable" de su experiencia y ha quedado, de algún modo, prendida a ella. La ventana, en cambio, le proporciona un puente hacia una realidad más bella, incontaminada, incapaz de desvalorizarse. Por ella logra elevar su existencia hacia las nubes cuyo paso es reiterado, casi obsesionante, a lo largo del relato. Ocasionalmente pueblan ese fragmento de cielo, palomas y gorriones, otra pareja en la que se manifiesta el dualismo ínsito en el cuento. Pero sobre todo, nubes, nubes de variadas formas y colores. Ellas conforman el objeto poético sustitutivo de la condición humana para el atribulado y decepcionado Michel. ${ }^{25}$ Parece innecesario caracterizarlas simbólicamente. Desde la antigüedad bíblica, pasando por todos los poetas de la historia, se ha reconocido al agua un valor purificador y a su continente aéreo, una connotación de belleza, pureza y libertad. Poetas tan distantes como San Francisco de Assis y Nicolás Guillén las han recogido de idéntica manera en su obra. Para Cortázar, parecen representar asimismo, el máximo de belleza imaginable, si juzgamos por la emoción que provocan a los "cronopios", sus criaturas predilectas."28

24 Pedro Salinas, Ensayos de literatura bispánica, Aguilar, Madrid, pp. 363-4.

25 Cortázar cita una carta de Keats en la que el poeta inglés afirma que "nunca ha esperado otra felicidad que la del puro presente" y en la que agrega como al descuido "si un gorrión se posa junto a mi ventana, tomo parte en su existencia y picoteo en el suelo..." ( $L a$ vuelta al dia en ocbenta mundos, p. 211). Este tomar parte en la existencia del gorrión es lo que hace Michel, primeramente, con el chico de la placita, ahora, con las nubes.

26 "Un cronopio iba a lavarse los dientes junto a su balcón y poseído de una grandísima alegria al ver el sol de la maniana $y$ las bermosas nubes que corrian por el cielo apretó enormemente el tubo de pasta dentífrica y la pasta empezó 2 salit en una larga cinta rosa. (...) Los pedazos de pasta rosa caian sobre los sombreros de las famas, mientras arriba el cronopio cantaba y se frotaba los dientes Ileno de contento" (J. Cortázar, "Lo particular y lo universal", Historia de cronopios y de famas. Minotauro, Buenos Aires, 1962).

En este breve trozo vemos contrapuestos dos símbolos recurrentes en Cortázar. De un lado, el acto de cepillarse los dientes, que, como ha notado José Amícola (Sobre Cortäzar. B. Aires, 1969, p. 117) es uno de sus símbolos preferidos para reflejar la cotidianeidad de la vida y lo repetitivo de la existencia humana. Del otro, el sol y las nubes (tal como en "Las babas del diablo") como elementos 
El insistente tratamiento que se le otorga en "Las babas del diablo", convierte a estas nubes en las sucesoras de aquellas, las más famosas de la literatura española, que son contempladas por Calixto, puesta la mano en la mejilla, desde el solejar de su casa. Nubes fugitivas que pasan lejos sobre el cielo azul, nubes que han permitido a Azorín recrearnos, con tanta levedad como fuerza, a los célebres amantes de La Celestina. ${ }^{27}$

$\mathrm{Si}$ cogemos al azar cualquiera de los diccionarios simbológicos al uso, leeremos, finalmente, definiciones como ésta:

.. .las nubes simbolizan las formas como fenómenos y apariencias, y como causantes de los vientos y las lluvias, simbolizan, asimismo, la fertilidad o fecundidad. En el simbolismo cristiano, las nubes son el velo natural del cielo azul, por lo que representan a Dios invisible. $^{28}$

Si tuviésemos que elegir entre los títulos con que se ha llamads a la versión española, "Las babas del diablo", y a la francesa, Les Fils de la Vierge, nos inclinatiamos por este último. ${ }^{29}$ is cierto que ambos representan una red dispuesta para atrapar a su víctima pero el primero muestra muy directamente el mal, personificado en un Lucifer a quien "se le hace agua la boca". En cambio, los hilos de la Virgen (expresión con la que en Francia se designa esos hilos blancos y ligeros que flotan en el aire en otoño, especie de telaraña delicada y bella) parecen conllevar mejor la apariencia amorosa de la mujer rubia, la dulzura de sus sabias caricias.

University of Maine

CARLOS CORTÍNEZ

naturales capaces de combatir tal monotonía y provocar irrefrenables estados de felicidad.

Z7 Azorín, Castilla. Aguilar, Obras Completas, Tomo II, p. 702.

28 J. A. Pérez-Rioja, Diccionatio de simbolos y mitos, Madrid, 1962, p. 267.

29 La versión inglesa adoptó el nombre Blow-up, sometiéndose de este modo al escogido por Antonioni para su film. La tentación de aprovechar el éxito comercial de un título, sospecho que es irresistible en paises donde la literatura es, ante todo, un artículo de consumo. En tales empresas nunca encuentra Mefistó feles rival que quiera luchar por el alma de unas cuantas palabras insignificantes. 